\title{
Nunavut government assailed over outbreak
}

$\mathrm{T}$ he government of Nunavut is "covering up" information indicating that a wave of flulike illness that is sweeping Nunavut's communities in recent weeks is actually an epidemic of respiratory syncytial virus (RSV), a Canadian infectious diseases expert charges.

Instead of releasing data on RSV in the territory, the government "is covering it up," says Dr. Anna Banerji, professor of pediatrics at the University of Toronto in Ontario. "I would find it very surprising if the recent deaths are not related to RSV."

Banerji urges that the government of Nunavut immediately adopt universal antibody coverage among Inuit infants and estimates that more than half of Nunavut's 26 communities have already been affected by the outbreak. RSV is the leading cause of lower respiratory tract infections in infants and young children. Nunavut suffers from the highest rate of RSV in the world.

But the territory's chief medical officer of health says that those infants who need treatment are receiving it.

RSV is carefully managed in the territory using monthly injections of palivizumab, an antibody that is provided to premature babies and infants with chronic heart or lung problems, says Dr. Isaac Sobol, adding that the territory's decision not to adopt universal coverage for all full-term Inuit infants younger than six months of age at the onset of the RSV season is based on an "internal review."

Moreover, Sobol adds that "we've seen RSV in Nunavut every year" and that caseloads have been dropping in number in recent years. "Our goal is to provide protection for those kids most vulnerable."

But Banerji says the government's management of RSV ignores both scientific evidence and a recommendation from the Canadian Pediatric Society.

The controversy erupted as a consequence of a trio of recent infant deaths, prompting Louis Tapardjuk, the mem-

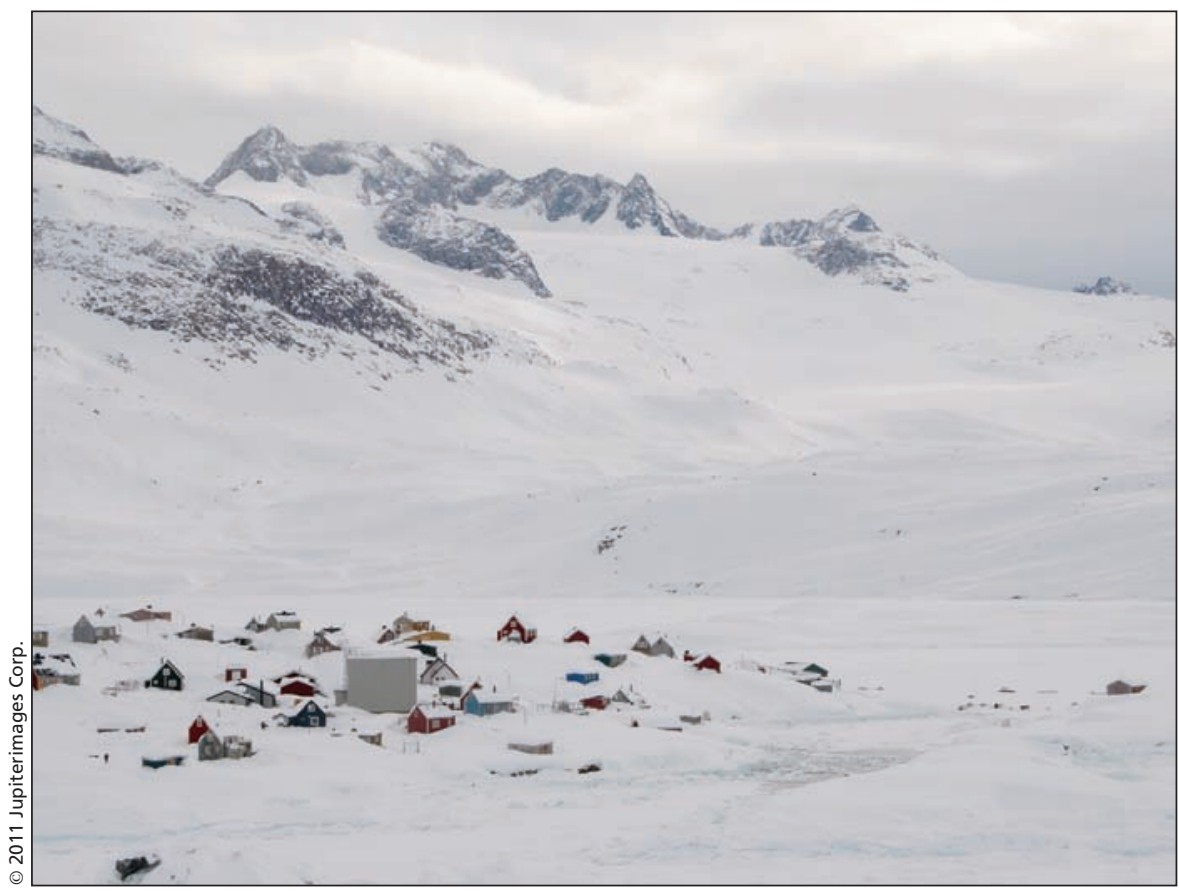

An estimated half of Nunavut's 26 communities have been affected by the outbreak. The remoteness of communities is believed to be a risk factor for respiratory syncytial virus.

ber of the Nunavut legislature for Igloolik, to demand a public inquiry into the cause of the outbreak. "I am asking whether or not they will try to get to the bottom of this," he told the legislature.

Nunavut Health Minister Tagak Curley has rejected calls for a public inquiry, in accordance with Sobol's advice that the government await the results from the coroner's office.

Banerji says the government's failure to proceed with universal antibody coverage on the grounds that there are a diminishing number of RSV cases is unjustified. "RSV fluctuates in waves from year to year and universal antibody coverage would reduce the risk of hospitalizations and deaths in the worst years, such as this one."

She also argues the diminishing number of RSV cases is a reflection of the impact of antibody usage among the most vulnerable infants, and should be grounds for universal coverage, rather than limitations on availability.

Banerji has linked RSV to such risk factors as smoking during pregnancy, rural residency, full Inuit Status and high levels of overcrowding among Inuit families in the Canadian Arctic (Pediatr Infect Dis J. 2009; 28[8]:697-701). The study also indicated that non-breastfed adopted children had a 4.4-fold increased risk over their breastfed, nonadopted counterparts.

In a separate study, Banerji established that universal antibody treatment for rural Inuit children would be more cost-effective than the current practice of selective treatment alongside extensive usage of air evacuations for sick children (J Med Econ 2009;12[4]:361-70).

Similarly, a 2009 Canadian Paediatric Society position statement asserts that "consideration should be given to administering prophylaxis to all fullterm Inuit infants younger than six months of age at the onset of the RSV season in northern remote communities (for example, children who require air transportation to hospital facilities).',

The position statement adds that there is insufficient data to "make rec- 
ommendations for other First Nations and Métis full-term infants living in remote communities. This is identified as an urgent research priority, and in the interim, some experts may recommend prophylaxis in these populations based on local epidemiology" (www .ncbi.nlm.nih.gov/pmc/articles/PMC27 80968/?tool=pubmed).
Banerji says Nunavut's refusal to provide new RSV data on RSV in Baffin Island, which is the only region in the territory with its own hospital, is compromising follow-up studies. Coinvestigator Dr. Michael Young of the IWK (Isaak Walton Killam) Health Centre in Halifax, Nova Scotia, says the data would be useful. "I cannot understand their reasons for denying this data."

But Sobol says the request for data was denied "because we were already underway with our internal review." Paul Christopher Webster, Toronto, Ont.

CMAJ 2011. DOI:10.1503/cmaj.109-3840 